\title{
Türk Üniversiteleri Sıralama Göstergelerinin Ağırlıklandırılması: University Ranking by Academic Performance (URAP) Türkiye Genel Siralaması Örneği"
}

\author{
Durmuş Özbaşı ${ }^{1}$, Barış Uslu ${ }^{1 *}$
}

1Eğitim Bilimleri Bölümü, Eğitim Fakültesi, Çanakkale Onsekiz Mart Üniversitesi, Çanakkale, ORCID: 0000-0001-5078-477X, 0000-0001-5941-1507

\begin{abstract}
Özet
Bu araştırmanın amacı,URAP Türkiye Genel Sıralaması́nda kullanılan puanlamagöstergelerinden istatistikselolarakanlamlıolanların belirlenmesi ve belirlenen göstergelerin yüzdelik olarak ağırlıklandırılmasıdır. Araştırma, URAP verilerinin ikincil kullanımına dayalı, regresyon modellemesi olarak tasarlanmıștır. Araștırmada kullanılan veri seti, 2010-2018 arası URAP Türkiye Genel Sıralamaları́na ait puanlar kullanılarak oluşturulmuştur. Türk üniversiteleri sıralaması için URAP tarafından kullanılan beş gösterge Makale, Toplam Atıf, Toplam Bilimsel Doküman, Doktora Mezun Öğrenci Sayısı ve Öğretim Üyesi/Öğrenci puanlarıdır. Bu göstergelere ait ilk yedi yılki puan ortalamaları hesaplanmış ve bu ortalamalar 2017-18 URAP Türkiye Genel Sıralaması toplam puanlarını açıklamak amacıyla bağımsız değișkenler olarak atanmıștır. Anlamlı göstergelerin hepsinin bir arada bulunduğu ve determinant katsayısı $\left(R^{2}\right)$ bire yakın en kapsamlı istatistiksel modelin belirlenmesi için Aşamalı [Stepwise] Regresyon Analizi kullanılmıștır. Analiz sonucunda, 2017-18 URAP Türkiye Genel Sıralaması toplam puanlarına ait varyansın tamamına yakınını $\left(R^{2}=, 942\right)$ açıklayan bir regresyon modeli elde edilmiştir. Beş göstergeden yalnızca Toplam Bilimsel Doküman Puanı bu modelde anlamlı (p>.05) gösterge olarak yer almamaktadır. Anlamlı göstergeler olan Makale, Toplam Atıf, Doktora Mezun Öğrenci Sayısı ve Öğretim Üyesi/Öğrenci puan ortalamalarına ait standardize edilmiș beta ( $\beta$ ) katsayıları kullanılarak bu göstergeler ağırlıklandırılmıștır. Anlamlı göstergelere ilişkin ağırlıklar Makale Puanı için \%47,83, Doktora Mezun Öğrenci Sayısı Puanı için \%33,61, Toplam Atıf Puanı için \%13,48 ve Öğretim Üyesi/Öğrenci Puanı için \%5,08 olarak hesaplanmıștır. Anlamlı göstergelere ait ağırlıklar kullanılarak yeniden hesaplanan 2017-18 gösterge puanlarının toplamı ile ağırlıklandırma ișlemi yapılmadan aynı göstergelere ait puanların toplamı üzerinden Türk üniversiteleri sıralamaları oluşturularak karșılaștırılmıștır. Yapılan karşılaştırmada, 19 üniversitenin aynı sırada yer aldığı ve 102 üniversitenin sıralamalarının bir ile 22 basamak arasında değiştiği belirlenmiştir.
\end{abstract}

Anahtar Sözcükler: Üniversite sıralamaları, URAP Türkiye Genel Sıralaması, Aşamalı Regresyon Modeli, yüzdelik ağırlıklandırma, ağırlıklı puanlama

\section{Weighting the Indicators of Turkish University Rankings: The Example of University Ranking by Academic Performance (URAP) Turkey General Rankings}

\begin{abstract}
The purpose of this research is to identify the statistically significant indicators in the URAP Turkey General Rankings and to weight these significant indicators as a percentage. This research was designed as a regression model based on the secondary usage of URAP data. The data set was generated from the scores in the URAP Turkey General Rankings between 2010 and 2018. Five indicators in the URAP Turkish Universities Ranking are Article, Total Citation, Total Scientific Document, The Number of Doctoral Graduates and Faculty/Student scores. For each indicator, the mean score of first seven years was determined, and these mean scores were assigned as independent variables to explain universities' total scores in the URAP Turkey General Rankings. Stepwise Regression Analysis was performed to establish the most comprehensive statistical model including all significant indicators together in order to attain the highest determinant $\left(\mathrm{R}^{2}\right)$ coefficient close to one. This analysis adjusted the regression model that explains nearly the entire variance $\left(R^{2}=.942\right)$ for the 2017-18 URAP Turkey General Rankings. Among five indicators, only Total Scientific Document Score ( $\mathrm{p}>$.05) is not a significant indicator in this model. As significant indicators, Article, Total Citation, The Number of Doctoral Graduates, and Faculty/Student scores were weighted using standardised beta $(\beta)$ coefficients for the mean scores of these four indicators. The weights for significant indicators were calculated $47.83 \%$ for Article, 33.61\% for The Number of Doctoral Graduate, 13.48\% for Total Citation, and 5.08\% for Faculty/Student scores. Two rankings were formed based on the sum of weighted 2017-18 scores for significant indicators and the sum of unweighted 2017-18 scores for significant indicators, and then these rankings were compared. The comparison revealed that 19 universities take same places in these two rankings, but the order of 102 universities in these rankings differ from one to 22 places.
\end{abstract}

Keywords: University rankings, URAP Turkey General Rankings, Stepwise Regression Model, percentage weighting, weighted scoring

*Yazışma Adresi / Address for Correspondence: Barış Uslu, Email: barisuslu@comu.edu.tr

Geliş Tarihi / Received Date: 13.04.2018

Kabul Tarihi / Accepted Date: 24.07.2018

Doi: $10.26701 /$ uad.414967

\section{Giriș}

Küresel bir pazar haline gelen günümüz yükseköğretim sektöründe, uluslararası sıralamalardaki konumları üniversitelerin tüm dünyadan öğrenci çekebilmek için geliştirdikleri reklam ve pazarlama stratejilerinin ayrılmaz 
bir parçasıdır (Chen, 2008; Harvey, 2008; Mampaey, Huisman, \& Seeber, 2015). Yine de yükseköğretim düzeyinde en çok uluslararası öğrenci ağırlayan ülkeler arasında yüzde olarak ilk sırada yer alan Avustralya'da bile 391.500 uluslararası öğrenciye karşın 1.065.709 ulusal öğrenci ile oran \%26,87'dir (DET, 2017). Doğal olarak, dünya genelinde üniversiteler için uluslararası öğrenciler kadar ulusal öğrencileri (hatta en iyilerini) çekebilmek ayrı bir önem taşımaktadır. Bu nedenle üniversite yöneticileri, uluslararası sıralamalardaki konumlarının yanı sıra, kurumlarının aynı ülkedeki diğer üniversitelerden daha başarılı olduğunu dile getirirken referans olarak genellikle ulusal üniversite sıralamalarını kullanmaktadır (Douglass, 2016; Karadağ, 2016; Williams, Leahy, Rassenfosse, \& de Jensen, 2016). Ulusal üniversite sıralamaları ise çoğunlukla daha fazla puan göstergesi içerdiğinden, büyük benzerlikler gösterseler de daha uzun soluklu olan ve belli bir metodolojiyi benimseyen uluslararası üniversite sıralamalarına göre teknik açıdan eleştiriye daha açı görünmektedir (Çakır, Acartürk, Alaşehir, \& Çilingir, 2015).

Uluslararası alanda birçok üniversite "dünya klasmanında üniversite [world-class university]" türü sloganlarını Times Higher Education (THE), Quacquarelli Symonds (QS), Shanghai Ranking (ARWU), Center for World University Rankings (CWUR), Consejo Superior de Investigaciones Científicas (Webometrics), US News, uniRank, Round University Ranking (RUR) gibi şirketler/ajanslar ile Hollanda'dan Leiden Üniversitesi ve Türkiye'den University Ranking by Academic Performance (URAP) gibi akademik birimler tarafından yapılan dünya üniversiteler siralamalarına dayandırmaktadırlar (Hazelkorn, 2015; Shattock, 2017; Shehatta \& Mahmood, 2016). Birçok çalışmada (Altbach \& Salmi, 2011; Salmi, 2009; Shin \& Khem, 2013) ise "dünya klasmanında üniversite" söyleminin temelini oluşturan özellikler ile bu uluslararası üniversite sıralamalarında sıkça kullanılan göstergelerin örtüşmediği dile getirilmektedir. Bu sıralamalar ayrıca öğretim kalitesini ölçmede yetersiz kaldıkları ve önemli sayılabilecek göstergelerden mezunların işe yerleşme düzeyini içermediği gibi eleştirilerle de karşı karşıyadır (Arkall-Olcay \& Bulu, 2016; Shin, Toutkoushian, \& Teichler, 2011; Uslu, 2017). Uluslararası üniversite sıralamalarının teorik temellerine yönelik bu tür eleştirilere ek olarak, bu sıralamalar, göstergelere ilişkin verilerin toplanması ve toplanan verilerin istatistiksel analizleri açısından da eleştirilmektedir (Bougnol \& Dula, 2015; Konan \& Yllmaz, 2017; Saka \& Yaman, 2011). Soh (2017) uluslararası üniversite sıralamalarına yönelik başlıca teknik sorunları "sahte hassaslık, ağırlık uyumsuzlukları, varsayımsal karşılıklı dengeleme, gösterge kullanımında aşırılık, sistemler arası tutarsızlık, gösterge puanların ihmali ve sıralamalarla toplam puanlardaki değişiklikler arasında tutarsızlık" şeklinde yedi başlık altında tanımlamaktadır.

Benzeri teorik ve teknik eleştiriler ülke bazlı üniversite sıralamaları için de söz konusudur. Örneğin; Mezuniyet ve Öğrenci Devam Oranları (\%22,5), Lisans Düzeyinde Aka- demik Ün (\%22,5), Fakülte Kaynakları (\%20), Öğrenci Alımında Seçicilik (\%12,5), Finansal Kaynaklar (\%10), Mezuniyet Oranı Performansı $(\% 7,5)$ ve Mezunların Bağıș Oranı (\%5) göstergelerine dayalı olarak US News (2017) tarafından yapılan Amerikan Üniversiteleri Siralaması'na yönelik "kapsamlı bir resim sunmaktan çok uzak" olduğu yönünde Amerikalı yükseköğretim uzmanları tarafından 2017'de ortaya konan ciddi bir eleştirel söylev göze çarpmaktadır (Strauss, 2017). Çakır vd. (2015) ise birçok ülkeden farklı ulusal ve uluslararası sıralamayı temele alarak gerçekleştirdikleri karşılaştırmalı çalışmada, ulusal üniversite sıralamalarının daha fazla gösterge içerme eğiliminde olmasına rağmen uluslararası sıralamalarla benzer şekilde gösterge çakışmaları, gösterge ağırlıklandırma(ma)ları, veri toplama araçlarının geçerlik-güvenirlik sorunları, istatistiki işlemlerde teknik eksiklikler gibi metodolojik sorunların varlığını dile getirmiștir. Söz konusu bu çalışma (Çakır vd., 2015), merkezi ülkemizde (Orta Doğu Teknik Üniversitesi Enformatik Enstitüsü) bulunan URAP Araştırma Laboratuvarı tarafindan yapılan World Ranking ve Türkiye Genel Sıralamaları örneklerini de içermektedir.

URAP (2017a) tarafından dünya üniversiteler sıralaması için Makale (\%21), Atıf (\%21), Toplam Doküman (\%10), Makale Etkisi Toplamı (\%18), Atıf Etkisi Toplamı (\%15) ve Uluslararası İşbirliği (\%15) şeklinde akademik performans odaklı bir gösterge seti kullanılması ve yüzde olarak bu göstergelere ait ağırlıklandırmaların açıklanmış olması, URAP World Ranking'in benzerlerine göre teorik ve metodolojik açıdan daha az eleştiriye maruz kalmasını sağlamaktadır (Shehatta \& Mahmood, 2016). Fakat URAP World Ranking ile URAP Türkiye Genel Sıralaması arasında hem göstergeler hem de istatistiksel yöntemler anlaminda farklılıklar söz konusudur. URAP Türkiye Genel Sıralaması gösterge seti dokuz farklı gösterge içermesine rağmen bazı göstergelerin ikili toplamlarının dikkate alınması sonucu üniversiteler Makale, Toplam Atıf, Toplam Bilimsel Doküman, Doktora Mezun Öğrenci Sayısı, Öğretim Üyesi/Öğrenci kategorilerinden puanlanmaktadır (URAP, 2017b). URAP World Ranking göstergelerinde yer almayan göstergeler de içerdiği görülen URAP Türkiye Genel Sıralaması'nda ülkemiz üniversitelerinin yeri, bu beş kategoriden elde ettikleri puanlar herhangi bir yüzdelik katkı gözetmeksizin doğrudan toplanarak belirlenmektedir.

Her ne kadar istatistiki açıdan anlamlı olup olmadıkları ve yüzdelik ağırlıklarının uygun olup olmadığı sorgulansa da (Bougnol \& Dula, 2015; Çakır vd., 2015; Saka \& Yaman, 2011; Shin vd., 2011; Soh, 2017), uluslararası üniversite sıralamalarında yapılan yüzdelik ağırlıklandırmalar gibi, ulusal sıralamalar için kullanılan göstergelerin istatistiksel kontrollerden geçirilerek ağırlıklandırılmaması teknik açıdan birçok soruna neden olabilecek bir durumdur. Alaşehir, Çakır, Acartürk, Baykal \& Akbulut (2014) tarafından yapılan ve URAP Türkiye Genel Sıralaması'ndaki üniversitelerin büyüklüğüne bağlı ve bağlı olmayan gös- 
tergelere ait yalnızca ortalamaların ve ranjların yer aldığı çalışmanın dışında, URAP Türkiye Genel Sıralaması'na ilişkin istatistiksel inceleme içeren herhangi bir çalışmaya rastlanmamıştır. Göstergelerinin katkıları ağırlıklandırılmadan yapılan bir sıralama için getirilebilecek en temel eleştirinin, söz konusu sıralamanın istatistiksel olarak doğru sonuçlar üretmede eksikler göstereceğidir. URAP Türkiye Genel Sıralaması'nın göstergelerinin istatistiksel işlemlere dayalı olarak belirlenmesi ve belirlenen göstergelerin yüzdeliklendirilerek puanlanması ile oluşturulması ise yapılan sıralamanın daha güvenilir ve geçerli hale gelmesine katkı sağlayacaktır.

Böylesi bir yüzdelikli ağırlıklandırmayı içerecek istatistiksel modellemelerde, uluslararası üniversite sıralamaları üzerine yapılmış olan çalışmaların birçoğunda regresyon modelleme yöntemi kullanılmıştır (Bougnal \& Dula, 2015; Shin vd., 2011; Soh, 2011; 2013a; 2013b). Regresyon modellemelerindeki birbirinden tamamen farklı en az iki veri türünden birinin diğerini açılaması (bir diğer ifade ile a'nın b'yi yordaması) temelli genel yaklaşımın aksine, bu tür çalışmalarda ilgili uluslararası üniversite sıralamalarındaki gösterge puanların üniversitelerin sıralama puanlarının tümünü açıklayacak şekilde modellenmesi amaçlanmaktadır. Bu çalışmalarda, teknik bir yaklaşımla, $\mathrm{a}_{\mathrm{g} 1}$, $\mathrm{a}_{\mathrm{g} 2}, \mathrm{a}_{\mathrm{g} 3}, \ldots$ bileşenlerinin $\mathrm{a}_{\mathrm{sp}}$ şeklindeki üniversite sıralama puanlarına ilişkin varyansın tamamının açıklandığı (determinant katsayısının $\left(\mathrm{R}^{2}\right)$ bir olduğu) regresyon modellemelerindeki Standardize Beta $(\beta)$ katsayıları üzerinden göstergelerin yüzdeliklendirilmesi yaklaşımı söz konusudur. Bu yaklaşımın temelini ise standardize edilmemiş $\beta$ katsayılarının (her ne kadar uluslararası sıralamalardaki yüzdelikleri tam olarak karşılasalar da) bir göstergenin diğer göstergelerle olan çoklu doğrusal bağlantıları [multi-collinearity] yansıtması, standardize $\beta$ katsayılarının bu tür göstergeler arası çoklu bağlantıları minimize eden değerler üretmesidir. Benzeri yaklaşım, URAP Türk Üniversiteleri Sıralama Göstergelerinin yüzdeliklendirilerek ağırlıklandırılması için de kullanılabilir. Bu tür bir çalışma ayrıca URAP Türk Üniversite Sıralaması Göstergelerinden istatistiksel olarak anlamlı olanların belirlenmesi ve ağırlıklandırmaların yalnızca anlamlı göstergeler üzerinden yapılmasını da sağlayacaktır. Bu bağlamda, URAP Türkiye Genel Sıralaması'nda kullanılan puanlama göstergelerinin istatistiksel olarak anlamlılığının incelenmesi ve anlamlı göstergelerin ağırlıklandırılması bu araştırmanın amacını oluşturmaktadır.

\section{YÖNTEM}

$\mathrm{Bu}$ araştırma, URAP verilerinin ikincil kullanımına dayali, regresyon modellemesi olarak tasarlanmıştır. Araştırma tasarımı doğrultusunda, 2010-2018 arasında URAP tarafından yayınlanmış Türk üniversiteleri sıralamalarına ait puanlamalar yapılan araştırmaya dahil edilmiştir. Elde edilen nicel veri seti üzerinde ise anlamlı puan göstergelerinin belirlenmesi ve bu göstergelerin ağırlıklandırılması amacıyla analizler gerçekleştirilmiştir.

\subsection{Veri Seti}

Veri setinin oluşturulması sürecinde, URAP tarafından 2010 ile 2018 arasında oluşturulan Türk üniversiteleri sıralamalarında aynı puanlama göstergelerinin ve büyük çoğunluğunda aynı veri kaynaklarının (ISI Web of Science çıtıları, YÖK istatistikleri, vb. (URAP, 2017b)) kullanıldığı tespit edilmiştir. Bu nedenle, URAP Türkiye Genel Sıralaması puanlamalarına ilişkin farklı yıllara ait veriler bir bütün halinde kullanıma uygundur. Böylesi uzun dönemli benzeşik verilerin ortak kullanımı, elde edilecek sonuçların boylamsal olarak tutarlığın sağlanmasına katkıda bulunacaktır.

Bu araştırmada da, sekiz yıla ait URAP Türkiye Genel Sıralamalarının tümünde yer alan üniversitelere ait gösterge puanlarından yararlanılmıștır. Türk üniversiteleri sıralamalarına ait verilerin tümüne URAP'ın web sayfasından (http://tr.urapcenter.org/) erişilmiştir. 2010-2011 yılından başlayarak URAP tarafından açıklanan toplamda 8 yıla ait tüm üniversite sıralamaları bilgisayar ortamına aktarılmıştır. MS Excel programından yararlanılarak 2018'e kadar olan sekiz yılın her biri için URAP tarafından beş farklı göstergedeki puanlamalar ve üniversitelerin toplam puanları ayrı ayrı sütunlar halinde düzenlenerek veri seti elde edilmiştir.

\section{2. Veri Analizi}

URAP Türkiye Genel Sıralamalarının tümünde bulunan 121 üniversiteye ait puanlar SPSS 18 programına aktarılarak beş göstergenin her biri için ayrı ayrı yedi yıllık (20172018 sıralama puanları dışında) ortalamaları hesaplanmıştır. Türk üniversitelerine ait bu uzun süreli ortalama puanlar kullanılarak, URAP tarafindan en son açıklanan 2017-2018 Türkiye Genel Sıralaması'ndaki üniversitelere ait toplam puanların belirleyicisi olan göstergeler çoklu regresyon analizi yapılarak ağırlıklandırılmıştır.

İlk olarak, çoklu regresyon analizi için gerekli varsayımların (Hair, Black, Babin, \& Anderson, 2010) karşılanıp karşılanmadığı kontrol edilmiştir: 1) beş değişkenli regresyon modeli için (50+[8x5değişken]) hesaplamasına göre 121 üniversite örneklem büyüklüğü açısından yeterlidir. 2) Bağımlı değişken konumundaki 2017-2018 URAP Türkiye Genel Sıralaması'ndaki üniversitelere ait puanlardan oluşan veriler, Kolmogorov-Smirnov testi sonuçlarına (ve ayrıca Skewness-Kurtosis değerlerine) göre normal dağılmaktadır (Tablo 1). Her ne kadar bağımsız değişkenler için önkoşul konumunda olmasa da, araştırmanın bağımsız değişkenlerini oluşturan (ve sürekli değişkenler olan) beş göstergenin her biri için de yedi yıllık ortalama puanların normalliği incelenmiş, Kolmogorov-Smirnov testi sonuçlarına (ve ayrıca Skewness-Kurtosis değerlerine) göre normal dağılım gösterdikleri belirlenmiștir. 3) Regresyon modelinde yer alan değişkenlerin arasındaki çoklu doğrusal bağlantı düzeyleri, Collinearity Statistic değerlerine (Tolerance $>, 10$ ve $\mathrm{VIF}<10$ kriterlerine) göre uygundur. 4) Analizdeki hata oranları arasında Durbin-Watson testi sonucuna ( $D-W \approx 2$ kriterine) göre otokorelasyon bu- 
lunmamaktadir.

Veri setinin regresyon analizine uygunluğunun kontrol edilmesinin ardından, Türk üniversitelerinin Makale, Toplam Atıf, Toplam Bilimsel Doküman, Doktora Mezunu Öğrenci Sayısı ve Öğretim Üyesi/Öğrenci kategorilerine ait yedi yıllık puan ortalamalarının 2017-2018 Türkiye Genel Sıralaması puanlarının yordayıcı göstergeleri olup olmadığına dair regresyon analizi yapılmıştır. Üniversitelerin 2017-2018 Türkiye Genel Sıralaması puanlarını anlamlı olarak açıklayan (yordayan) en iyi modelin belirlenmesi amacıyla da Çoklu Doğrusal Regresyon Analizi tekniklerinden biri olan Aşamalı [Stepwise] Regresyon Analizi tercih edilmiştir. $\mathrm{Bu}$ analiz ile belirlenen anlamlı göstergelere ait regresyon katsayıları kullanılarak URAP Türkiye Genel Sıralaması Göstergeleri'nin ağırlıkları hesaplanmıştır. Belirlenen yüzdelik ağırlıklar kullanılarak 2017-2018 URAP Türkiye Genel Siralaması Gösterge puanları yeniden hesaplanmış ve elde edilen ağırlıklandırılmış puanların toplamı üzerinden Türk üniversiteleri sıralaması yeniden düzenlenmiştir.

\section{BULGULAR}

Analiz aşamasında ilk olarak, URAP Türkiye Genel Sıralaması kapsamında 2010-11 ile 2016-17 arasında üniversitelerin beş farklı kategorideki yedi yıllık puanlarına ait ortalamalar hesaplanmıştır. Daha sonra, bu ortalamaların basıklık ve çarpıklık katsayıları incelenmiş ve ayrıca Kolmogorov-Smirnov testi uygulanmıştır. Bu işlemler ile elde edilen bulgular aşağıda Tablo 1'de verilmiştir. ortalamalarının üzerindedir. Tablo 1'de yer alan gösterge puan ortalamalarının normal dağılım sergilemesi ise, 121 Türk üniversitesi için ortalama puanların istatistiki işlemlere uygunluğunu olumsuz etkileyebilecek uç değerlerin göz ardı edilebilecek düzeyde olduğunu göstermektedir.

$\mathrm{Bu}$ belirlemeden sonra, yedi yıllık puan ortalamaları kullanılarak 2017-2018 URAP Türkiye Sıralaması'ndaki üniversite puanlarını yordama düzeylerini incelemek için Çoklu Regresyon Analizi tekniklerinden Aşamalı Regresyon Analizi tercih edilmiştir. Bu tercihin nedeni, URAP tarafından kullanılan beş gösterge arasında açıklanmış bir öncelik sırası bulunmadığından, analiz sürecinde Așamalı Regresyon ile en güçlü yordayıcı değiş̧kenden oluşan tek değişkenli modelden başlanarak, tüm anlamlı değişkenleri içeren en kapsamlı ve en güçlü modele doğru bir modelleme sıralamasının oluşturulmasıdır. Yapılan analiz sonucu oluşan ve 2017-18 URAP Türkiye Genel Siralaması üniversite puanlarına ilişkin varyansı açıklayan anlamlı modellere ait bulgular Tablo 2'de özetlenmiștir.

Uluslararası üniversite sıralamaları üzerinde yapılmış benzer çalışmalarda (Bougnal \& Dula, 2015; Shin vd., 2011; Soh, 2011; 2013a; 2013b) atanmış yüzdeliklerin istatistiksel uygunluğu, çoğunlukla standardize edilmemiş $\beta$ katsayılarının (atanmış yüzdelikler) regresyon analizi ile elde edilen standardize $\beta$ katsayıları ile karşılaştırılması yoluyla incelenmiştir. URAP tarafından Türk üniversiteleri sıralama göstergelerine ilişkin hali hazırda atanmış yüzdelikler olmadığından standardize edilmemiş $\beta$ katsayılarına Tablo 2'de yer verilmemiştir.

Tablo 1. 2010-11 ile 2017-18 Arası URAP Türkiye Genel Sıralama Göstergelerine İlişkin İstatistikler ${ }^{\dagger}$

\begin{tabular}{|c|c|c|c|c|c|}
\hline Gösterge & Puan Ortalaması $^{\Pi}$ & s.s. & $\begin{array}{c}\text { Kolmogorov-Smirnov Değer- } \\
\text { leri* }^{*}\end{array}$ & Çarpıklık Değeri ${ }^{*}$ & Basıklık Değeri \\
\hline Makale & 86,40 & 33,68 & $Z=, 575 ; p=, 895$ &,- 091 &,- 606 \\
\hline Toplam Atıf & 83,22 & 40,54 & $Z=1,020 ; p=, 249$ & 141 &,- 740 \\
\hline Toplam Bilimsel Doküman & 83,44 & 38,79 & $Z=, 973 ; p=, 300$ & ,229 &,- 689 \\
\hline Doktora Mezun Öğrenci Sayısı & 63,42 & 47,84 & $Z=1,020 ; p=, 249$ & ,489 &,- 549 \\
\hline Öğretim Üyesi/Öğrenci & 50,23 & 12,96 & $Z=1,052 ; p=, 219$ &, 537 & ,418 \\
\hline 2017-18 Göstergeleri & 2017-18 Puan Ortalaması & s.s. & $\begin{array}{c}\text { Kolmogorov-Smirnov Değer- } \\
\text { leri* }^{*}\end{array}$ & Çarpıklık Değeri & Basıklık Değeri \\
\hline Makale & 98,05 & 36,76 & $Z=, 604 ; p=, 859$ & ,082 &,- 120 \\
\hline Toplam Atıf & 104,22 & 37,27 & $Z=, 514 ; p=, 955$ & 112 &,- 258 \\
\hline Toplam Bilimsel Doküman & 100,74 & 35,73 & $Z=, 735 ; p=, 653$ & ,073 &,- 592 \\
\hline Doktora Mezun Öğrenci Sayısı & 72,44 & 49,21 & $Z=, 782 ; p=, 574$ & ,481 &,- 444 \\
\hline Öğretim Üyesi/Öğrenci & 50,81 & 16,95 & $Z=1,073 ; p=, 200$ &,- 251 & 946 \\
\hline 2017-18 Toplam Puanları & $426,26 !$ & 148,67 & $Z=, 989 ; p=, 282$ & ,403 &,- 519 \\
\hline
\end{tabular}

†URAP Türkiye Genel Sıralamalarının tümünde yer alan 121 üniversiteye ait veriler kullanılmıştır.

П2010-2011 ile 2016-2017 arası gösterge puanlarına ait 7 yıllık ortalamalar

'Yordanan değişken için 2017-18 toplam puanlara ait ortalama

Normal Dağılım $\rightarrow{ }^{*} \mathrm{p}>, 05 ;{ }^{*}-2<\mathrm{ÇD}<+2,-2<\mathrm{BD}<+2$

Tablo 1'de yer alan göstergelere ilişkin puanlamaların üst sınırları URAP tarafından açıkça belirtilmediğinden, URAP Türkiye Genel Sıralaması puan ortalamalarının hangi düzeyde olduğuna ilişkin değerlendirme olanağ bulunmamaktadır. Diğer taraftan, veri setindeki üniversitelerden 65'i Makale ve Toplam Atıf, 61'i Toplam Bilimsel Doküman, 57'si Doktora Mezun Öğrenci Sayısı ve 51'i Öğretim Üyesi/Öğrenci kategorisinde yedi yıllık puan
2017-2018 URAP Türkiye Genel Sıralaması'ndaki üniversite puanlarını maksimum düzeyde açıklayan (yordayan) modele $\left(\mathrm{F}_{(4-116)}=468,448 ; \mathrm{p} \leq, 05\right)$ ilişkin Tablo 2'de yer alan bulgulara göre, analize katılan beş göstergeden yalnızca 'yedi yıllık Toplam Bilimsel Doküman puan ortalaması' anlamlı yordayıcı olarak regresyon modelinde yer almamaktadır. Diğer taraftan, Aşamalı Regresyon Analizi sürecinde göstergeler arasından yalnızca en güçlü yordayıcı 
Tablo 2. 2017-18 URAP Türkiye Genel Sıralaması Üniversite Puanlarına İlişkin Regresyon Analizi!

\begin{tabular}{|c|c|c|c|c|c|c|}
\hline \multirow[t]{2}{*}{ Modeller } & \multirow[t]{2}{*}{ Anlamlı Gösterge(ler) } & \multirow[t]{2}{*}{$\beta$} & \multirow[t]{2}{*}{$\mathrm{t}$} & \multirow[t]{2}{*}{$\mathrm{p}$} & \multicolumn{2}{|c|}{ Collinearity } \\
\hline & & & & & Tolerance $^{*}$ & VIF $^{\dagger}$ \\
\hline $\begin{array}{c}\text { Model 1 } \rightarrow \text { R: }, 946 ; \mathbf{R}^{2}:, 895 \\
\mathbf{F}_{(1-119)}: 1.013,085 ; \mathbf{p}:, 000^{*} ; \mathbf{D}-\mathbf{W}^{\Pi}:-\end{array}$ & $\begin{array}{c}\text { 2010-17 Toplam Bilimsel Doküman Puan } \\
\text { Ortalaması }\end{array}$ & 946 & 31,829 &, $000^{*}$ & 1,000 & 1,000 \\
\hline \multirow[t]{2}{*}{$\begin{array}{c}\text { Model } 2 \rightarrow \mathbf{R}:, 960 ; \mathbf{R}^{2}:, 921 ; \\
\mathbf{F}_{(2-118)}: 687,295 ; \mathbf{p}:, 000^{*} ; \mathbf{D}-\mathbf{W}^{\Pi}:-\end{array}$} & $\begin{array}{c}\text { 2010-17 Toplam Bilimsel Doküman Puan } \\
\text { Ortalaması }\end{array}$ & 739 & 17,550 &, $000^{*}$ & ,378 & 2,646 \\
\hline & $\begin{array}{c}\text { 2010-17 Doktora Mezun Öğrenci Sayısı } \\
\text { Puanı Ortalaması }\end{array}$ & ,263 & 6,237 &, $000^{*}$ & ,378 & 2,646 \\
\hline \multirow[t]{3}{*}{$\begin{array}{c}\text { Model } 3 \rightarrow \mathbf{R}:, 969 ; \mathbf{R}^{2}:, 938 \\
\mathbf{F}_{(3-117)}: 594,129 ; \mathbf{p}:, 000^{*} ; \mathbf{D}-\mathbf{W}^{\Pi}:-\end{array}$} & $\begin{array}{c}\text { 2010-17 Toplam Bilimsel Doküman Puan } \\
\text { Ortalaması }\end{array}$ & 191 & 1,869 &, 064 & ,050 & 19,840 \\
\hline & $\begin{array}{c}\text { 2010-17 Doktora Mezun Öğrenci Sayısı } \\
\text { Puanı Ortalaması }\end{array}$ & 350 & 8,689 &, $000^{*}$ & ,324 & 3,086 \\
\hline & 2010-17 Makale Puanı Ortalaması &, 500 & 5,758 &, $000^{*}$ & 070 & 14,294 \\
\hline \multirow[t]{4}{*}{$\begin{array}{c}\text { Model } 4 \rightarrow \text { R: }, 970 ; \mathbf{R}^{2}:, 941 \\
\mathbf{F}_{(4-116)}: 458,614 ; \mathbf{p :}, 000^{*} ; \mathbf{D}-\mathbf{W}:-\end{array}$} & $\begin{array}{c}\text { 2010-17 Toplam Bilimsel Doküman Puan } \\
\text { Ortalaması }\end{array}$ & 145 & 1,407 & 162 & 048 & 20,819 \\
\hline & $\begin{array}{c}\text { 2010-17 Doktora Mezun Öğrenci Sayısı } \\
\text { Puanı Ortalaması }\end{array}$ & ,356 & 8,927 &, $000^{*}$ & 322 & 3,101 \\
\hline & 2010-17 Makale Puanı Ortalaması &, 522 & 6,050 &, $000^{*}$ & 069 & 14,538 \\
\hline & $\begin{array}{c}\text { 2010-17 Öğretim Üyesi/Öğrenci Puanı } \\
\text { Ortalaması }\end{array}$ &, 050 & 2,036 & ,044* & 838 & 1,193 \\
\hline \multirow[t]{3}{*}{$\begin{array}{c}\text { Model 5 } \rightarrow \text { R: ,969; R²: ,940; } \\
\mathbf{F}_{(3-117)}: 605,751 ; \mathbf{p : ~}, 000^{*} ; \mathbf{D}-\mathbf{W}:-\end{array}$} & $\begin{array}{c}\text { 2010-17 Doktora Mezun Öğrenci Sayısı } \\
\text { Puanı Ortalaması }\end{array}$ & ,391 & 12,400 &, $000^{*}$ &, 521 & 1,919 \\
\hline & 2010-17 Makale Puanı Ortalaması & ,635 & 19,825 &, $000^{*}$ &, 504 & 1,986 \\
\hline & $\begin{array}{c}\text { 2010-17 Öğretim Üyesi/Öğrenci Puanı } \\
\text { Ortalaması }\end{array}$ &, 058 & 2,388 &, $019^{*}$ & 879 & 1,137 \\
\hline \multirow{4}{*}{$\begin{array}{c}\text { Model } 6 \rightarrow \text { R: }, 970 ; \mathbf{R}^{2}:, 942 ; \\
\mathbf{F}_{(4-116)}: 468,448 ; \mathbf{p :}, 000^{*} \\
\text { D-Wח: } 2,216\end{array}$} & $\begin{array}{c}\text { 2010-17 Doktora Mezun Öğrenci Sayısı } \\
\text { Puanı Ortalaması }\end{array}$ & 364 & 10,799 &, $000^{*}$ & ,444 & 2,254 \\
\hline & 2010-17 Makale Puanı Ortalaması &, 518 & 8,038 &, $000^{*}$ & ,121 & 8,261 \\
\hline & $\begin{array}{c}\text { 2010-17 Öğretim Üyesi/Öğrenci Puanı } \\
\text { Ortalaması }\end{array}$ & 055 & 2,301 &, $023^{*}$ & 877 & 1,141 \\
\hline & 2010-17 Toplam Atıf Puanı Ortalaması & 146 & 2,088 &, $039^{*}$ & ,103 & 9,736 \\
\hline
\end{tabular}

URAP Türkiye Genel Sıralamaları'nın tümünde yer alan 121 üniversiteye ait veriler kullanılmıştır.

${ }^{*} \mathrm{p} \leq, 05 ;{ }^{*}$ Tolerance $>, 10 ;{ }^{\dagger} \mathrm{VIF}<10 ;{ }^{\mathrm{T}} \mathrm{D}-\mathrm{W} \approx 2$

içeren ilk modelde 'Toplam Bilimsel Doküman puan ortalaması' $(t=31,829 ; \mathrm{p} \leq, 05)$ yer almaktadır. Yine iki değișkenli ikinci modelde 'Toplam Bilimsel Doküman puan ortalaması' $(t=17,550 ; \mathrm{p} \leq, 05)$ ile 'Doktora Mezun Öğrenci Sayısı puan ortalaması' $(t=6,237 ; \mathrm{p} \leq, 05)$ birlikte anlamlı yordayıcılar olarak yer almaktadır. 'Toplam Bilimsel Doküman' ile 'Doktora Mezun Öğrenci Sayısı' puan ortalamalarına 'Makale puan ortalaması' eklendiğinde oluşan üçüncü modelde ise 'Toplam Bilimsel Doküman puan ortalaması' $(t=1,869 ; \mathrm{p}=, 06[>, 05])$ anlamlı yordayıcı olarak yer almamaktadır.

2017-18 URAP Türkiye Genel Sıralaması'ndaki 121 üniversitenin toplam puanlarına ilişkin açıllama oranı en fazla olan modele (Model 6) ait Tablo 2'de yer alan bulgulara göre, Makale $(t=8,038 ; \mathrm{p} \leq, 05)$, Doktora Mezun Öğrenci Sayısı $(t=10,799 ; \mathrm{p} \leq, 05)$, Toplam Atıf $(t=2,088$; $\mathrm{p} \leq, 05)$ ve Öğretim Üyesi/Öğrenci $(t=2,301 ; \mathrm{p} \leq, 05)$ puan ortalamaları anlamlı yordayıcılardır. Bu yordayıcıların regresyon modeline tek başına katkılarını daha net değerlendirebilmek için Standardize Edilmiş Beta Katsayıları dikkate alınmış ve bu katsayılar ile bu katsayıların toplamları üzerinden dört yordayıcı gösterge için yüzdelik ağırlıklandırma yapılmıștır. Yapılan ağırlıklandırmaya göre, 2017-18 Türk Üniversiteleri Sıralaması'na yordayıcı göstergelerin katkılarının Makale Puanı için \%47,83 ([,518/1,083]x100), Doktora Mezun Öğrenci Sayısı Puanı için \%33,61 ([,364/1,083]x100), Toplam Atıf Puanı için \%13,48 ([,146/1,083]x100) ve Öğretim Üyesi/Öğrenci Puanı için \%5,08 ([,055/1,083]x100) olduğu hesaplanmıştır. $\mathrm{Bu}$ değerler kullanıldığında oluşan formül aşağıdaki gibidir.

Üni. Sıralama Puanı $=($ Makale P. x 0,4783 $)+($ Dr Mezun P. $x$ $0,3361)+($ Atıf P. x 0,1348) +(Öğrt.Üyesi/Öğr. P. x 0,0508)

Belirlenen yüzdelikler kullanılarak dört yordayıcı gösterge için 2017-2018 URAP Türkiye Genel Sıralama Gösterge Puanları yeniden hesaplanmış ve hesaplanan puanlara göre yapılan sıralama ile 2017-18 URAP Türkiye Genel Sıralaması'ndaki ilgili dört yordayıcı göstergenin ağırlıklandırılmadan toplanması ile olușturulan sıralama karşılaştırmalı olarak ekler bölümünde (Ek 1) sunulmuştur. Yapılan karşılaştırmada her iki sıralamada da ilk beş sırada olan yükseköğretim kurumlarının aynı üniversiteler olduğu görülmektedir. Bu beș üniversite dışında 121 üniversite içerisinde 14 üniversite daha her iki sıralamada da aynı sırada yer almaktadır. Yapılan yeni sıralamada yerleri değişen 102 üniversitenin sıralamaları bir ile 22 basamak arasında değişmektedir. Yeni sıralamada yukarı yönlü en büyük ilerleme 22 basamak iken, aşağı yönlü en 
büyük değișiklik 14 basamak olarak belirlenmiștir. Benzer şekilde, dört yordayıcı göstergeye ilişkin ağırlıklandırılmış puanlar üzerinden bu çalışmada oluşturulan sıralama ile URAP tarafından tüm gösterge puanlarının toplamı üzerinden oluşturulmuş olan 2017-2018 Türkiye Genel Sıralaması karşılaştırıldığında da 121 üniversite içinden 104'ünün sıralamadaki yerlerinin bir ile 22 basamak arasında değiştiği görülmüştür.

\section{SONUÇ, TARTIŞMA VE ÖNERILER}

Bu çalışmada, URAP Türkiye Genel Sıralaması Göstergeleri'ne ilişkin puanlamaların istatistiksel incelemesi yapılmıştır. Gerçekleştirilen istatistiksel incelemeye, URAP tarafından ilk yapılan Türk üniversiteleri sıralamasından başlayarak süreklilik arz eden beş gösterge setine ait puanlamalar temel oluşturmaktadır. 2010'dan başlayarak URAP tarafından sekiz yıldır kullanılan göstergelere ilişkin puanlamaların son yıl hariç yedi yıllık ortalamaları, son yıl (2017-18) URAP Türkiye Genel Sıralaması'ndaki 121 üniversitenin toplam puanlarının potansiyel yordayıcıları olarak regresyon analizine dahil edilmiştir. Elde edilen istatistiksel sonuçlar üzerinden birçok teknik detay (modellerin çıktılarının yakınlığı, göstergeler arası çoklu doğrusal bağlantılar, üniversitelerin puan gruplamaları vb.) farklı tartışma konuları olmasına rağmen, bu araştırmanın amacını uygun olarak URAP Türkiye Genel Sıralaması'ndaki anlamlı göstergelere uygulanabilecek yüzdelik ağırlıklandırmalar ve anlamlı göstergelerin öne çıkmasına yol açan olası nedenler aşağıda ele alınmıştır.

URAP Türk üniversiteleri sıralamalarından elde edilen yedi yıllık puan ortalamaları kullanılarak yapılan regresyon analizindeki standardize beta $(\beta)$ katsayıları kullanılarak, yordayıcı göstergelere ilişkin katsayısı hesaplamalarının boylamsal olarak da değerlendirilmesi sağlanmıştır. URAP Türk üniversiteleri sıralaması göstergelerine ilişkin belirtilmiş puan sınırları bulunmadığından, regresyon analizine alınan beş göstergeye ait puan ortalamaları üzerinden düzey değerlendirmesi ise yapılamamıștır. Beş gösterge için belirlenen ortalamalara bakıldığında; 121 üniversitenin yarısından fazlası Makale, Toplam Atıf ve Toplam Bilimsel Doküman puan kategorilerinde ortalamanın üzerindeyken, Doktora Mezun Öğrenci Sayısı ve Öğretim Üyesi/Öğrenci puan kategorilerinde üniversitelerin yarısından fazlasının ortalamanın altında yer aldığı görülmektedir. Bu durum, mevcut öğretim üyeleri bilimsel üretim konusunda başarılı bir performans sergilese de, Türk üniversitelerinin önemli bir bölümünde yeterli öğretim üyesi bulunmayışının öğretim üyesi/öğrenci oranının fazlalığı yanında az sayıda doktora programı açılabilmesine ve bu programlarda bilimsel üretimin kısıtlı kalmasına neden olarak üniversitelerin sıralamadaki yerlerini büyük ölçüde etkilediğini göstermektedir. Ayrıca, bu sonuç, URAP Türkiye sıralaması ile ilgili Alaşehir vd. (2014) tarafından yapılan tanımlamanın aksine, 'doktora öğrencilerinin toplam öğrenci sayısına oranı ile 'öğretim üyesi başına düşen öğrenci sayısı' göstergelerinin üniver- sitelerin kurumsal boyutları ile ilgili ve sıralamalardaki yeri açısından önemli göstergeler olduğunu göstermektedir. Çakır vd. de (2015), hem ulusal hem de uluslararası sıralamalarda öğrenci/öğretim üyesi oranın kullanılan sıralama göstergelerinin başında geldiğini ve akredite edilmiş doktora programı sayısının da ulusal sıralamalarda sık kullanılan belirleyici göstergelerden biri olduğunu belirtmişlerdir.

Diğer taraftan, 2017-2018 URAP Türkiye Genel Sıralaması Toplam Puanları'na ilişkin yedi yıllık gösterge puan ortalamaları üzerinden yapılan Aşamalı Regresyon Analizi sonucu oluşan modelde yordayıcı gösterge olarak yer almayan tek gösterge 'Toplam Bilimsel Doküman Puan' ortalamasıdır. Makale Puanı ortalamasının regresyon modeline girişiyle birlikte bu göstergenin istatistiksel açıdan anlamlılığını yitirdiği belirlenmiştir. $\mathrm{Bu}$ bulgunun, bilimsel dokümanlar arasında makale sayısının asıl belirleyici unsur olduğunu gösterdiği söylenebilir. Ayrıca, araştırmacıların konferanslarda aldıkları dönütler sonrası bildirilerini geliştirerek, akademide daha prestijli olan hakemli dergilerde makale haline getirmeyi tercih etmelerinin makale sayısının etkisini arttırdığı da düşünülebilir. Harley \& Acord'un (2011) da belirttiği gibi, Yayınlarsın ya da Silinip Gidersin [Publish or Perish] (McGrail, Rickard, \& Jones, 2006) anlayışının hakim olduğu günümüz bilim dünyasında hakemli yayınların akademik başarının ve kariyer ilerlemesinin temeli konumunda oluşunun ise, Makale Puanı ortalamasının URAP Türkiye Genel Sıralaması'na yönelik regresyon modelindeki en güçlü yordayıcı gösterge olarak karşımıza çıkmasına neden olduğu iddia edilebilir.

Elde edilen en kapsamlı regresyon modelindeki bir diğer yordayıcı gösterge de, Moed (2005) tarafından makalelerin etki düzeyleri hakkında temel gösterge olarak tanımlanan 'Atıf Puanı' ortalamasıdır. Modeldeki dört göstergenin anlamlılık (yordayıcılık) düzeylerine dayalı olarak oluşturulan ağırlıklandırmada ise, yüzdelik değerler sırasıyla Makale Puanı için 47,83, Doktora Mezun Öğrenci Sayısı Puanı için 33,61, Toplam Atıf Puanı için 13,48 ve Öğretim Üyesi/Öğrenci Puanı için 5,08 şeklindedir. Hem ulusal hem de uluslararası sıralamaların büyük bölümünde yer alan bu göstergelere ilişkin ağırlıklandırma yapılmaması birçok araştırmacı tarafından (Bougnol \& Dula, 2015; Konan \& Yılmaz, 2017; Saka \& Yaman, 2011; Shin vd., 2011) önemli bir teknik eksiklik olarak görülmektedir. Soh (2011; 2013a; 2013b) ise üniversite siralamalarındaki göstergelerin ve bu göstergelere ilişkin yüzdeliklerin uygunluğunun istatistiksel modellemeler ile gözden geçirilmesinin daha sağlıklı sonuçlar elde edilmesine katkı sağlayacağını belirtmektedir. Bu araştırmada da, toplam puanlara dayalı olan URAP Türkiye Genel Sıralaması'nın istatistiksel olarak daha güvenilir sonuçlar üretmesine katı sağlamak amacıyla, kullanılan göstergelerin anlamlılığı değerlendirilmekte ve anlamlı olan göstergelere ilişkin ağırlıklandırma katsayıları önerilmektedir. 
Bu araştırmada önerilen katsayılar kadar, araştırmacılar tarafından URAP Türkiye Genel Sıralaması puan çıktıları üzerinde değişik istatistiksel yöntemler kullanılarak geliştirilecek alternatif ağırlıklandırmaların da Türk üniversiteleri sıralamasını oluşturan URAP ekibine değerli öneriler sağlayacağı açıktır. Araştırmacılar URAP Türkiye Genel Sıralaması'na yönelik geliştirecekleri alternatif ağırlıklandırmalar ile bu çalışmada ortaya çıkan katsayıları da karşılaştırabilirler. Temel regresyon yaklaşımına ( $a, b, c, \ldots$ değişkenleri x değişkenini ne oranda açıllar) uygun olarak, araştırmacılar yine URAP Türkiye Genel Sıralaması gösterge puanlarını benzer bir ulusal üniversite sıralama çıktıkları ile karşılaştırmak için kullanabilirler. Bu kapsamda, URAP Türkiye Genel Siralamasına benzer alternatif Türk üniversiteleri sıralamalarının başında ise Karadağ \& Yücel $(2016 ; 2017 ; 2018)$ tarafindan olușturulan ve Karadağ, Yücel, \& Belenkuyu (2018) tarafindan özetlenmiş olan Türk Devlet Üniversiteleri Akademik Teşvik Puan Sıralaması gelmektedir. Ayrıca, araştırmacılar bu araştırmadaki regresyon analizi yaklaşımını kullanabilecekleri gibi alternatif istatistiksel modellemeleri ulusal ölçekli sıralamaların ötesinde, göstergelerine ilişkin ham puanları yayınlayan uluslararası üniversite sıralamaları üzerinde de sinayabilirler.

\section{KAYNAKÇA}

Alaşehir, O., Çakır, M. P., Acartürk, C., Baykal, N., \& Akbulut, U. (2014). URAP-TR: A national ranking for Turkish universities based on academic performance. Scientometrics, 101, 159-178. doi:10.1007/s11192-014-1333-4

Altbach, P. G., \& Salmi, J. (Eds.). (2011). The road to academic excellence: The making of worldclass research universities. Washington, DC: The World Bank.

Arkalı-Olcay, G., \& Bulu, M. (2016). Uluslararası üniversite sıralama endekslerinde Türk üniversitelerinin yeri. Yükseköğretim Dergisi, 6, 95-103. doi:10.2399/yod.16.003

Bougnol, M.-L., \& Dula, J. H. (2015). Technical pitfalls in university rankings. Higher Education, 69, 859-866. doi:10.1007/ s10734-014-9809-y

Chen, L.-H. (2008). Internationalization or international marketing? Two frameworks for understanding international students' choice of Canadian universities. Journal of Marketing for Higher Education, 18, 1-33. doi:10.1080/08841240802100113

Çakır, M. P., Acartürk, C., Alaşehir, O., \& Çilingir, C. (2015). A comparative analysis of global and national university ranking systems. Scientometrics, 103, 813-848. doi:10.1007/ s11192-015-1586-6

DET (Department of Education and Training). (2017). Enrolment count by citizenship category. 22 Aralık 2017 tarihinde http://highereducationstatistics.education.gov.au/ adresinden erişilmiştir.

Douglass, J. A. (Ed.). (2016). The new flagship university changing the paradigm from global ranking to national relevancy. London: Palgrave Macmillan.

Hair, J. F., Black, W. C., Babin, B. J., \& Anderson, R. E. (2010). Multivariate data analysis (7th ed.). Upper Saddle River, NJ: Pearson Prentice Hall.
Harley, D., \& Acord, S. K. (2011). Peer review in academic promotion and publishing: Its meaning, locus, and future. University of California, Berkeley: Center for Studies in Higher Education.

Harvey, L. (2008). Rankings of higher education institutions: A critical review. Quality in Higher Education, 14, 187-207. doi:10.1080/13538320802507711

Hazelkorn, E. (2015). Rankings and the reshaping of higher education: The battle for world-class excellence. New York: Palgrave MacMillan.

Karadağ, N. (2016). Examining the branding of Turkish universities in the context of socio-economic development of their cities. International Journal of Higher Education, 5, 173-182. doi:10.5430/ijhe.v5n4p173

Karadağ, E., \& Yücel, C. (2016). Devlet üniversiteleri sıralaması: 2016 yılı. 06 Nisan 2018 tarihinde https://www.enginkaradag.net/dus adresinden erişilmiştir.

Karadağ, E., \& Yücel, C. (2017). Devlet üniversiteleri ve fakülteleri sıralaması [DÜS] 2017. Eskişehir. 06 Nisan 2018'de https:// www.uniar.net/dus adresinden erișilmiştir.

Karadağ, E., \& Yücel, C. (2018). Devlet üniversiteleri ve fakülteleri sıralaması [DÜS] 2018. Üniversite Araştırmaları Laboratuvarı Yayınları. doi:10.13140/RG.2.2.17310.84804

Karadağ, E., Yücel, C., \& Belenkuyu, C. (2018). Üniversite sıralamasında akademik teşvik puanlarının kullanılması: Devlet Üniversiteleri ve Fakülteleri Sıralaması [DÜS-2018]. Üniversite Araştırmaları Dergisi, 1, 31-35. doi:10.26701/ uad.401249

Konan, N., \& Yılmaz, S. (2017). Üniversitelerin sıralanma ölçütleri ve Türkiye üniversiteleri için öneriler. Yükseköğretim ve Bilim Dergisi, 7, 200-210. doi:10.5961/jhes.2017.199

Mampaey, J., Huisman, J., \& Seeber, M. (2015). Branding of Flemish higher education institutions: A strategic balance perspective. Higher Education Research \& Development, 34, 1178-1191. doi:10.1080/07294360.2015.1024634

McGrail, M. R., Rickard, C. M., \& Jones, R. (2006). Publish or perish: A systematic review of interventions to increase academic publication rates. Higher Education Research \& Development, 25, 19-35. doi:10.1080/07294360500453053

Moed, H. F. (2005). Citation analysis in research evaluation. Dordrecht: Springer.

Saka, Y., \& Yaman, S. (2011). Üniversite sıralama sistemleri; Kriterler ve yapılan eleştiriler. Yükseköğretim ve Bilim Dergisi, 1, 72-79. doi:10.5961/jhes.2011.012

Salmi, J. (2009). The challenge of establishing world-class universities. Washington, DC: The World Bank.

Shattock, M. (2017). The 'world class' university and international ranking systems: What are the policy implications for governments and institutions? Policy Reviews in Higher Education, 1, 4-21. doi:10.1080/23322969.2016.1236669

Shehatta, I., \& Mahmood, K. (2016). Correlation among top 100 universities in the major six global rankings: Policy implications. Scientometrics, 109, 1231-1254. doi:10.1007/s11192016-2065-4

Shin, J. C., \& Khem, B. M. (Eds.). (2013). Institutionalization of world-class university in global competition. Dordrecht: Springer.

Shin, J. C., Toutkoushian, R. K., \& Teichler, U. (Eds.). (2011). Uni- 
versity rankings: Theoretical basis, methodology and impacts on global higher education. Dordrecht: Springer.

Soh, K. C. (2011). Don't read university rankings like reading football league tables: Taking a close look at the indicators. Higher Education Review, 44, 15-29.

Soh, K. (2013a). Misleading university rankings: Cause and cure for discrepancies between nominal and attained weights. Journal of Higher Education Policy and Management, 35, 206-214. doi:10.1080/1360080X.2013.775929

Soh, K. (2013b). Rectifying an honest error in world university rankings: A solution to the problem of indicator weight discrepancies. Journal of Higher Education Policy and Management, 35, 574-585. doi:10.1080/1360080X.2013.844670

Soh, K. (2017). The seven deadly sins of world university ranking: A summary from several papers. Journal of Higher Education Policy and Management, 39, 104-115. doi: $10.1080 / 1360080 X .2016 .1254431$

Strauss, V. (2017, Ağustos 17). U.S. News's College Rankings face competition and criticism. The Washington Post. 22 Aralık 2017 tarihinde http://www.washingtonpost.com/wp-dyn/
content/article/2007/08/16/AR2007081602537.html adresinden erişilmiştir.

URAP. (2017a). World Ranking Indicators. 22 Aralık 2017 tarihinde http://urapcenter.org/2017/methodology.php?q=3 adresinden erişilmiştir.

URAP. (2017b). 2017-2018 Türkiye Genel Sıralaması Göstergeleri. 02 Ekim 2017 tarihinde http://tr.urapcenter. org/2017/2017.php adresinden erişilmiştir.

Uslu, B. (2017). Appearing in international rankings: How do academics from high-ranked universities comment? The 2 . International Higher Education Studies Conference, 12-14 October, Antalya, Turkey.

US News. (2017). How U.S. News calculated the 2018 Best Colleges Rankings? 22 Aralık 2017 tarihinde https://www.usnews. com/education/best-colleges/articles/how-us-news-calculated-the-rankings adresinden erişilmiştir.

Williams, R., Leahy, A., Rassenfosse, G., \& de Jensen, P. (2016). U21 ranking of national higher education systems 2016. Melbourne: University of Melbourne

Ek 1. 2017-18 URAP Türkiye Genel Sıralaması Gösterge Puanları ile Ağırlıklandırılmış Puanlara Göre Oluşan 121 Üniversitelik Sıralamalar

\begin{tabular}{|c|c|c|c|c|c|c|c|c|c|c|c|c|c|}
\hline \multirow{2}{*}{$\begin{array}{c}\text { Üniversite(si) } \\
\text { ODTÜ }\end{array}$} & \multicolumn{2}{|c|}{ URAP Puanları* } & \multirow{2}{*}{$\begin{array}{c}\text { Sira } \\
\text { No** }^{* *}\end{array}$} & \multirow{2}{*}{$\begin{array}{c}\begin{array}{c}\text { Sira } \\
\text { No*** }^{* *}\end{array} \\
1\end{array}$} & \multicolumn{2}{|c|}{$\begin{array}{l}\text { Ağırlıklandırılmış } \\
\text { Puan**** }\end{array}$} & \multirow{2}{*}{$\begin{array}{c}\text { Üniversite(si) } \\
\text { Pamukkale }\end{array}$} & \multicolumn{2}{|c|}{ URAP Puanları* } & \multirow{2}{*}{$\begin{array}{c}\text { Sira } \\
\text { No** }^{* *}\end{array}$} & \multirow{2}{*}{$\begin{array}{c}\begin{array}{c}\text { Sira } \\
\text { No*** }^{* *}\end{array} \\
32 \\
\end{array}$} & \multicolumn{2}{|c|}{$\begin{array}{l}\text { Ağırlıklandırıl- } \\
\text { mış Puan }\end{array}$} \\
\hline & 613,69 & $(798,01)$ & & & 181,22 & $(100,00)$ & & 384,80 & $(509,30)$ & & & 109,26 & $(60,29)$ \\
\hline Hacettepe & 607,93 & $(787,43)$ & 2 & 2 & 173,85 & $(95,93)$ & ÇOMÜ & 381,65 & $(499,95)$ & 35 & 35 & 105,61 & $(58,28)$ \\
\hline ітÜ & 570,12 & $(737,09)$ & 3 & 3 & 167,42 & $(92,38)$ & Manisa CBÜ & 379,63 & $(495,64)$ & 36 & 36 & 104,77 & $(57,81)$ \\
\hline İstanbul & 552,95 & $(716,57)$ & 4 & 4 & 161,38 & $(89,05)$ & Yüzüncü Yıl & 378,39 & $(493,97)$ & 37 & 37 & 100,59 & $(55,50)$ \\
\hline Ankara & 546,00 & $(698,63)$ & 5 & 5 & 157,53 & $(86,93)$ & Başkent & 377,02 & $(515,35)$ & 38 & 44 & 95,24 & $(52,56)$ \\
\hline Gebze Teknik & 537,61 & $(696,41)$ & 6 & 7 & 153,44 & $(84,67)$ & Gaziosmanpaşa & 363,62 & $(476,88)$ & 39 & 38 & 100,07 & $(55,22)$ \\
\hline Ege & 530,37 & $(684,86)$ & 7 & 10 & 147,60 & $(81,45)$ & Atılım & 360,87 & $(485,43)$ & 40 & 39 & 98,50 & $(54,36)$ \\
\hline ì. D. Bilkent & 529,48 & $(702,06)$ & 8 & 8 & 152,01 & $(83,88)$ & K. Sütçü İmam & 356,72 & $(461,23)$ & 41 & 40 & 98,32 & $(54,26)$ \\
\hline Gazi & 524,82 & $(678,67)$ & 9 & 6 & 156,12 & $(86,15)$ & Abant İÜ & 356,25 & $(472,29)$ & 42 & 41 & 96,39 & $(53,19)$ \\
\hline Boğaziçi & 519,56 & $(671,89)$ & 10 & 9 & 149,58 & $(82,54)$ & RTEÜ & 354,38 & $(463,63)$ & 43 & 46 & 94,69 & $(52,25)$ \\
\hline Koç & 505,24 & $(669,06)$ & 11 & 14 & 139,76 & $(77,12)$ & Düzce & 354,36 & $(467,68)$ & 44 & 50 & 93,19 & $(51,43)$ \\
\hline Sabancı & 504,59 & $(665,72)$ & 12 & 12 & 141,32 & $(77,98)$ & TOBB ETÜ & 354,05 & $(474,98)$ & 45 & 48 & 94,55 & $(52,17)$ \\
\hline Atatürk & 495,62 & $(632,74)$ & 13 & 11 & 142,31 & $(78,53)$ & Cumhuriyet & 353,65 & $(467,69)$ & 46 & 43 & 95,75 & $(52,84)$ \\
\hline Erciyes & 487,65 & $(637,42)$ & 14 & 15 & 138,69 & $(76,53)$ & Balıkesir & 349,50 & $(458,75)$ & 47 & 42 & 95,92 & $(52,93)$ \\
\hline Yıldız Teknik & 484,20 & $(627,93)$ & 15 & 13 & 141,15 & $(77,89)$ & Mustafa Kemal & 342,81 & $(465,93)$ & 48 & 60 & 87,51 & $(48,29)$ \\
\hline İzmir YTE & 483,16 & $(612,94)$ & 16 & 16 & 136,57 & $(75,36)$ & Muğla SKÜ & 340,23 & $(448,50)$ & 49 & 45 & 95,18 & $(52,52)$ \\
\hline Dokuz Eylül & 461,85 & $(596,35)$ & 17 & 19 & 130,87 & $(72,22)$ & Mersin & 339,78 & $(445,03)$ & 50 & 52 & 89,84 & $(49,58)$ \\
\hline Selçuk & 458,72 & $(605,91)$ & 18 & 17 & 133,52 & $(73,68)$ & Dumlupınar & 338,94 & $(445,03)$ & 51 & 47 & 94,60 & $(52,20)$ \\
\hline Marmara & 457,67 & $(591,75)$ & 19 & 18 & 131,98 & $(72,83)$ & Sinop & 338,53 & $(431,03)$ & 52 & 64 & 81,89 & $(45,19)$ \\
\hline Çukurova & 449,22 & $(581,37)$ & 20 & 20 & 128,14 & $(70,71)$ & Adnan Menderes & 334,72 & $(436,84)$ & 53 & 51 & 90,89 & $(50,15)$ \\
\hline Karadeniz Teknik & 442,31 & $(574,61)$ & 21 & 21 & 125,01 & $(68,98)$ & Çankaya & 333,54 & $(451,97)$ & 54 & 58 & 87,88 & $(48,49)$ \\
\hline Firat & 435,85 & $(564,95)$ & 22 & 26 & 117,95 & $(65,09)$ & Kırıkkale & 332,06 & $(438,38)$ & 55 & 49 & 94,33 & $(52,06)$ \\
\hline E. Osmangazi & 427,21 & $(556,70)$ & 23 & 25 & 118,16 & $(65,20)$ & Namık Kemal & 331,43 & $(433,80)$ & 56 & 59 & 87,81 & $(48,45)$ \\
\hline Süleyman Demirel & 424,81 & $(552,59)$ & 24 & 22 & 122,12 & $(67,39)$ & Bülent Ecevit & 329,24 & $(437,18)$ & 57 & 54 & 88,93 & $(49,07)$ \\
\hline Ondokuz Mayıs & 419,76 & $(553,61)$ & 25 & 23 & 119,53 & $(65,96)$ & Ömer Halisdemir & 327,99 & $(428,44)$ & 58 & 55 & 88,59 & $(48,88)$ \\
\hline Anadolu & 418,47 & $(525,34)$ & 26 & 27 & 117,38 & $(64,77)$ & Harran & 326,10 & $(436,43)$ & 59 & 62 & 82,17 & $(45,34)$ \\
\hline Uludağ & 411,76 & $(540,80)$ & 27 & 28 & 116,59 & $(64,34)$ & Afyon Kocatepe & 324,12 & $(438,54)$ & 60 & 57 & 88,51 & $(48,84)$ \\
\hline İnönü & 411,76 & $(536,46)$ & 28 & 30 & 115,25 & $(63,60)$ & Özyeğin & 322,04 & $(423,80)$ & 61 & 53 & 89,31 & $(49,28)$ \\
\hline Sakarya & 410,75 & $(535,79)$ & 29 & 24 & 118,89 & $(65,60)$ & Galatasaray & 316,61 & $(385,74)$ & 62 & 68 & 76,57 & $(42,26)$ \\
\hline Akdeniz & 404,25 & $(542,94)$ & 30 & 31 & 110,65 & $(61,06)$ & Hitit & 315,14 & $(410,47)$ & 63 & 61 & 85,88 & $(47,39)$ \\
\hline Dicle & 397,27 & $(529,15)$ & 31 & 34 & 107,75 & $(59,46)$ & Yeditepe & 314,52 & $(429,72)$ & 64 & 56 & 88,57 & $(48,88)$ \\
\hline Gaziantep & 396,09 & $(526,58)$ & 32 & 29 & 115,65 & $(63,82)$ & Doğuş & 314,29 & $(422,15)$ & 65 & 67 & 77,43 & $(42,73)$ \\
\hline Kocaeli & 388,36 & $(517,76)$ & 33 & 33 & 107,85 & $(59,51)$ & Aksaray & 303,63 & $(399,01)$ & 66 & 66 & 80,49 & $(44,42)$ \\
\hline
\end{tabular}


Ek 1 (devamı). 2017-18 URAP Türkiye Genel Sıralaması Gösterge Puanları ile Ağırlıklandırılmış Puanlara Göre Oluşan 121 Üniversitelik Sıralamalar

\begin{tabular}{|c|c|c|c|c|c|c|c|c|c|c|c|c|c|}
\hline \multirow{2}{*}{$\begin{array}{c}\text { Üniversite(si) } \\
\text { Trakya }\end{array}$} & \multicolumn{2}{|c|}{ URAP Puanları* } & \multirow{2}{*}{$\begin{array}{c}\begin{array}{c}\text { Sira } \\
\text { No** }^{* *}\end{array} \\
67\end{array}$} & \multirow{2}{*}{$\begin{array}{c}\begin{array}{c}\text { Sira } \\
\mathrm{No}^{* * *}\end{array} \\
63\end{array}$} & \multicolumn{2}{|c|}{$\begin{array}{l}\text { Ağılıılandırılmış } \\
\text { Puan**** }\end{array}$} & \multirow{2}{*}{$\begin{array}{l}\text { Üniversite(si) } \\
\text { Artvin Çoruh }\end{array}$} & \multicolumn{2}{|c|}{ URAP Puanları* } & \multirow{2}{*}{$\begin{array}{c}\begin{array}{c}\text { Sira } \\
\text { No** }^{* *}\end{array} \\
95\end{array}$} & \multirow{2}{*}{$\begin{array}{c}\begin{array}{c}\text { Sira } \\
\text { No** }^{* *}\end{array} \\
97\end{array}$} & \multicolumn{2}{|c|}{$\begin{array}{l}\text { Ağırlıklandırıl- } \\
\text { mış Puan**** }\end{array}$} \\
\hline & 301,61 & $(405,22)$ & & & 82,06 & $(45,28)$ & & 232,41 & $(285,75)$ & & & 56,35 & $(31,10)$ \\
\hline C. Karatekin & 295,00 & $(372,27)$ & 68 & 69 & 72,96 & $(40,26)$ & Hakkari & 231,21 & $(281,47)$ & 96 & 110 & 45,73 & $(25,24)$ \\
\hline İstanbul Bilim & 291,41 & $(400,76)$ & 69 & 76 & 68,57 & $(37,84)$ & Amasya & 229,50 & $(298,33)$ & 97 & 102 & 53,24 & $(29,38)$ \\
\hline Bahçeşehir & 281,93 & $(384,55)$ & 70 & 65 & 80,98 & $(44,69)$ & Okan & 222,56 & $(277,17)$ & 98 & 96 & 57,59 & $(31,78)$ \\
\hline Bozok & 281,68 & $(387,78)$ & 71 & 77 & 67,97 & $(37,51)$ & Batman & 211,65 & $(279,89)$ & 99 & 104 & 49,16 & $(27,12)$ \\
\hline Nevşehir HBVÜ & 280,76 & $(365,22)$ & 72 & 75 & 68,62 & $(37,87)$ & Mehmet Akif Ersoy & 211,49 & $(285,16)$ & 100 & 98 & 54,46 & $(30,05)$ \\
\hline Yalova & 275,64 & $(345,64)$ & 73 & 72 & 71,40 & $(39,40)$ & Mimar Sinan GSÜ & 207,62 & $(231,29)$ & 101 & 105 & 48,96 & $(27,02)$ \\
\hline Adıyaman & 272,89 & $(371,99$ & 74 & 74 & 69,11 & $(38,13)$ & İstanbul Bilgi & 206,49 & $(274,40)$ & 102 & 80 & 67,41 & $(37,20)$ \\
\hline Erzincan & 266,77 & $(343,82)$ & 75 & 73 & 70,49 & $(38,90)$ & Ağrı Ibrahim Çeçen & 205,53 & $(279,18)$ & 103 & 106 & 48,91 & $(26,99)$ \\
\hline Kadir Has & 265,56 & $(356,32)$ & 76 & 71 & 72,05 & $(39,76)$ & İstanbul Arel & 203,98 & $(259,08)$ & 104 & 93 & 60,22 & $(33,23)$ \\
\hline Bingöl & 261,55 & $(336,88)$ & 77 & 81 & 67,17 & $(37,07)$ & Siirt & 202,33 & $(264,66)$ & 105 & 108 & 47,82 & $(26,39)$ \\
\hline Bartın & 260,88 & $(336,82)$ & 78 & 85 & 65,73 & $(36,27)$ & Ufuk & 200,98 & $(272,49)$ & 106 & 114 & 38,92 & $(21,48)$ \\
\hline O. Korkut Ata & 258,93 & $(341,22)$ & 79 & 83 & 66,52 & $(36,71)$ & B. Şeyh Edebali & 199,97 & $(254,50)$ & 107 & 111 & 45,44 & $(25,07)$ \\
\hline Karabük & 255,34 & $(330,18)$ & 80 & 70 & 72,86 & $(40,21)$ & Kilis 7 Aralık & 194,12 & $(265,06)$ & 108 & 101 & 53,60 & $(29,58)$ \\
\hline Ordu & 254,26 & $(338,85)$ & 81 & 78 & 67,87 & $(37,45)$ & Çağ & 191,07 & $(239,06)$ & 109 & 99 & 54,25 & $(29,93)$ \\
\hline Bitlis Eren & 254,01 & $(334,60)$ & 82 & 91 & 60,91 & $(33,61)$ & Uşak & 186,49 & $(239,86)$ & 110 & 107 & 48,16 & $(26,57)$ \\
\hline Kafkas & 252,71 & $(347,68)$ & 83 & 82 & 66,67 & $(36,79)$ & İstanbul Ticaret & 184,01 & $(253,99)$ & 111 & 103 & 51,62 & $(28,48)$ \\
\hline Giresun & 251,12 & $(320,91)$ & 84 & 87 & 63,57 & $(35,08)$ & Iğdır & 174,18 & $(222,71)$ & 112 & 117 & 36,17 & $(19,96)$ \\
\hline Ahi Evran & 248,18 & $(334,42)$ & 85 & 95 & 58,66 & $(32,37)$ & İstanbul Aydın & 173,17 & $(218,93)$ & 113 & 109 & 46,06 & $(25,42)$ \\
\hline K. Mehmetbey & 246,64 & $(336,58)$ & 86 & 84 & 65,85 & $(36,34)$ & İstanbul Kültür & 170,77 & $(237,56)$ & 114 & 112 & 45,35 & $(25,02)$ \\
\hline Gümüşhane & 246,07 & $(332,20)$ & 87 & 92 & 60,66 & $(33,47)$ & Ardahan & 170,74 & $(205,04)$ & 115 & 115 & 38,13 & $(21,04)$ \\
\hline Maltepe & 244,23 & $(310,68)$ & 88 & 86 & 65,11 & $(35,93)$ & Muş Alparslan & 163,68 & $(214,31)$ & 116 & 116 & 36,30 & $(20,03)$ \\
\hline Işık & 242,59 & $(327,76)$ & 89 & 88 & 63,06 & $(34,80)$ & Kırklareli & 153,21 & $(208,16)$ & 117 & 119 & 33,01 & $(18,21)$ \\
\hline İzmir Ekonomi & 242,41 & $(337,24)$ & 90 & 79 & 67,87 & $(37,45)$ & Haliç & 147,77 & $(187,52)$ & 118 & 113 & 41,84 & $(23,09)$ \\
\hline Yaşar & 237,32 & $(315,53)$ & 91 & 89 & 61,56 & $(33,97)$ & Şırnak & 136,26 & $(177,96)$ & 119 & 121 & 22,84 & $(12,60)$ \\
\hline Kastamonu & 235,62 & $(307,45)$ & 92 & 94 & 59,90 & $(33,06)$ & Mardin Artuklu & 134,96 & $(161,74)$ & 120 & 120 & 24,95 & $(13,77)$ \\
\hline Munzur & 235,31 & $(306,16)$ & 93 & 100 & 54,20 & $(29,91)$ & Beykent & 128,21 & $(168,04)$ & 121 & 118 & 35,94 & $(19,83)$ \\
\hline Bayburt & 233,50 & $(304,62)$ & 94 & 90 & 61,41 & $(33,89)$ & & & & & & & \\
\hline
\end{tabular}

* Buradaki puanlar, anlamlı dört göstergenin 2017-18 puanlarının toplanması ile oluşturulmuştur. URAP Türkiye Genel Sıralaması puanları ise parantez içinde sunulmuştur.

** Anlamlı göstergelere ait 2017-18 puan toplamları kullanılarak URAP Türkiye sıralamalarının tümünde yer alan 121 üniversite için yeniden oluşturulmuştur.

*** Dört gösterge için belirlenen yüzdelik ağırlıklandırmaların ilgili 2017-18 URAP Türkiye Genel Sıralaması Gösterge Puanları́na uygulanması ile oluşturulan sıralamadır.

**** Elde edilen ağırlıklandııımış puanlar, göstergelere ait ham puanlamaların 100 üzerinden yapılmamış olması nedeniyle 100 puanın üzerinde çıkabilmektedir. Ağırlıklandırılmış puanlara göre ilk sırada yer alan üniversitenin puanı 100 olarak kabul edildiğinde 100 üzerinden oluşan puanlar parantez içinde sunulmuştur. 